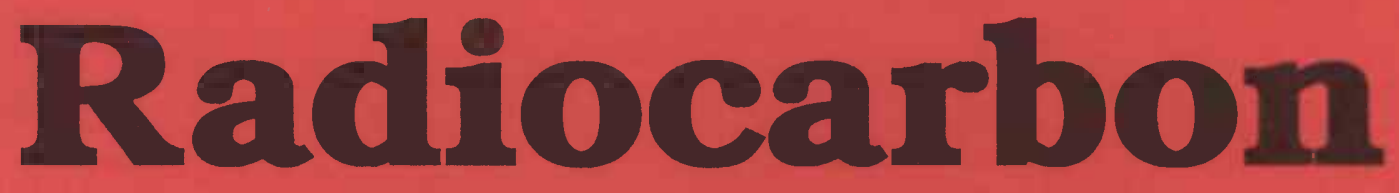

An' International Jourrial of Cösmogenic Is.otope Researrch

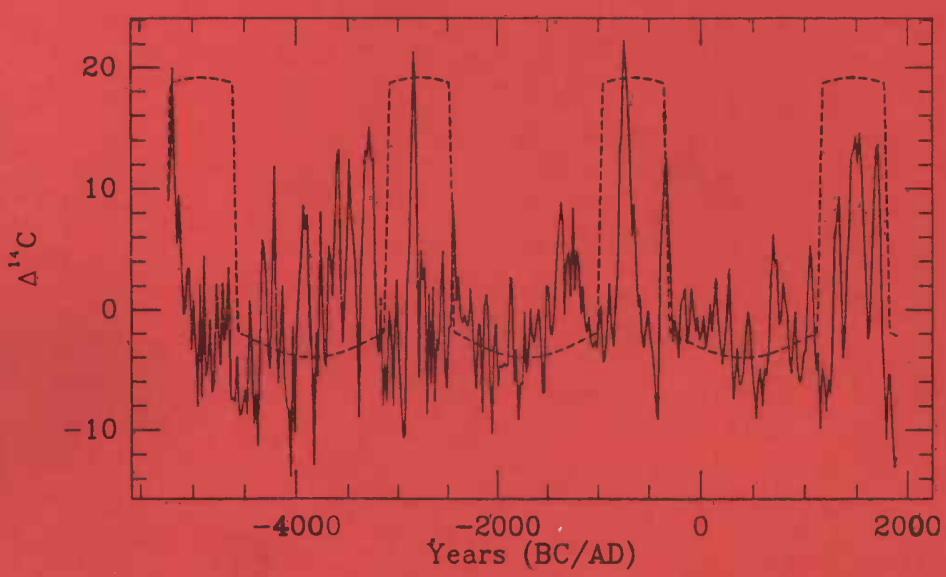

\title{
PALEOASTROPHYSICS, PALEOGEOPHYSICS
}

Proceedingigs of the Wọrkshop, Paleoastrophysics and Natural Variations of Cosmogenicg Isotopes

Edited by Paul E. Damon, Austin Long and Renee S. Kra Assistant Editor - Frances D. Moskovitz
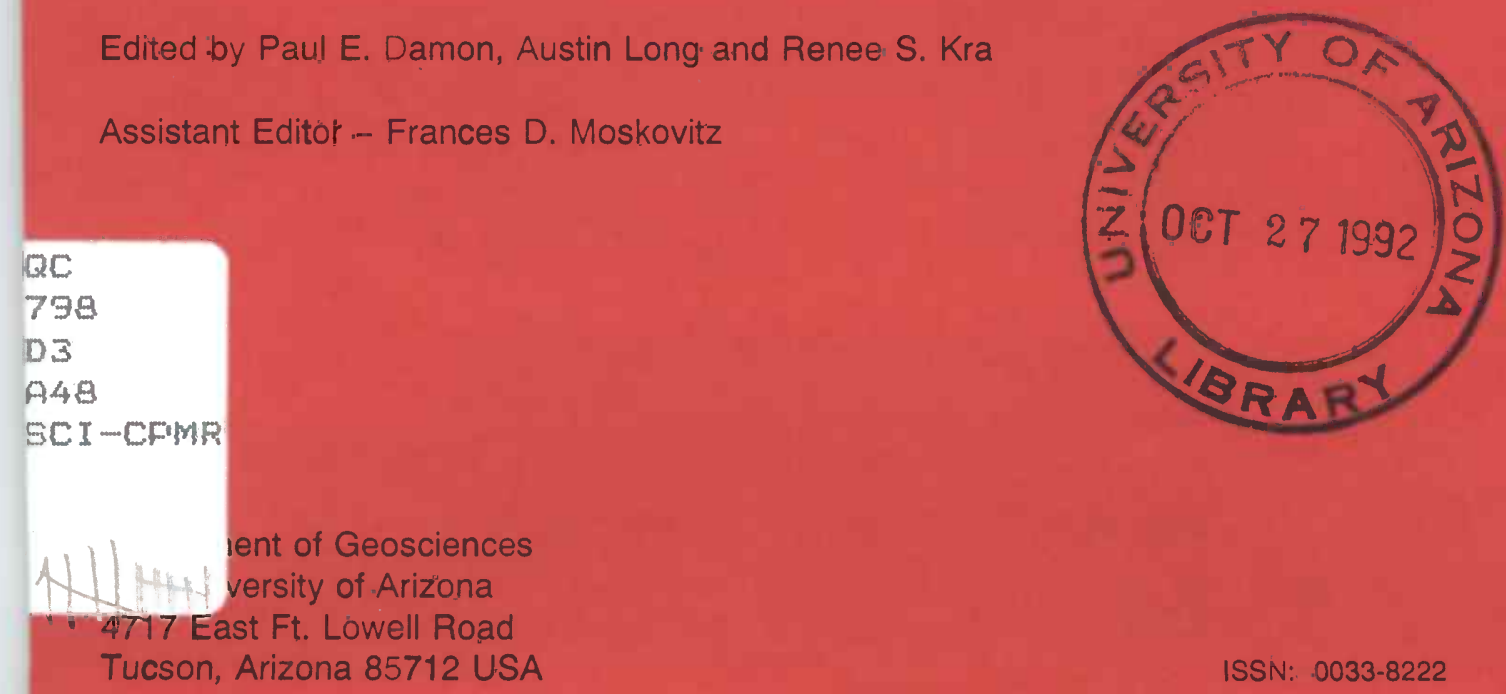


\title{
RADIOCARBON
}

\section{An International Journal of Cosmogenic Isotope Research}

\author{
Editor: AUSTIN LONG \\ Managing Editor: RENEE S. KRA \\ Assistant Editor: FRANCES D. MOSKOVITZ \\ Published by \\ Department of Geosciences \\ The University of Arizona
}

Published three times a year at The University of Arizona, Tucson, AZ 85712 USA. (1) 1992 by the Department of Geosciences, The University of Arizona.

Subscription rate $\$ 105.00$ (for institutions), $\$ 73.50$ (for individuals), $\$ 36.75$ (for students with proper identification). Foreign postage is extra. A complete price list, including Proceedings of International Conferences, appears in the back of this issue.

Back issues and price lists may be obtained from the office of RADIOCARBON.

All correspondence and manuscripts should be addressed to the Managing Editor, RADIOCARBON, Department of Geosciences, The University of Arizona, 4717 East Ft. Lowell Road, Tucson, AZ 85712 USA. Tel: (602) 881-0857; Please note our new BITNET address: C14@ARIZVMS; Fax: (602) 881-0554.

Offprints. The minimum offprint order for each article will be 100 copies without covers. No offprints will be furnished free of charge unless page charges are paid. The cost of additional copies will, of course, be greater if the article is accompanied by plates involving unusual expense. Copies will be furnished with a printed cover giving the title, author, volume, page and year, when specially ordered.

Page charges. Each institution sponsoring research reported in a technical paper or a date list, will be asked to pay a charge of $\$ 80.00$ per printed page. Institutions or authors paying such charges will be entitled to 100 free offprints without covers. No charges will be made if the author indicates that the author's institution is unable to pay, and payment of page charges on an article will not in any case be a condition for its acceptance. Reduced rates will be in effect for some special issues.

Missing issues will be replaced without charge only if claim is made within three months (six months for India and Australia) after the publication date. Claims for missing issues will not be honored if absence results from failure by the subscriber to notify the Journal of an address change.

Illustrations should include explanation of symbols used. Copy that cannot be reproduced cannot be accepted. Whenever possible, reduce figures for direct publication. Line drawings should be in bląck India ink on white drawing board, tracing cloth, or coordinate paper printed in blue and should be accompanied by clear ozalids or reduced photographs for use by the reviewers. Photographs should be positive prints. Figures (photographs and line drawings) should be numbered consecutively through each article, using Arabic numerals. All meäsurements should be given in SI (metric units). Tables may be accepted as camera-ready copy.

Citations. A number of radiocarbon dates appear in publications without laboratory citation or reference to published date lists. We ask that laboratories remind submitters and users of radiocarbon dates to include-proper citation (laboratory number and date-list citation) in all publications in which radiocarbon dates appear

Radiocarbon Measurements: Comprehensive Index, 1950-1965. This index covers all published ${ }^{14} \mathrm{C}$ measurements through Volume 7 of RADIOCARBON, and incorporates revisions made by all laboratories. It is available at $\$ 25.00$ per copy.

List of laboratories. Our comprehensive list of laboratories is available upon request. We are expanding the list to include additional laboratories and scientific agencies with whom we have established contacts. The editors welcome more information on these or other scientific organizations. We ask all laboratory directors to provide their telephone, telex and fax numbers as well as their E-mail addresses. Changes in names or addresses, additions or deletions should also be reported to the Managing Editor. 


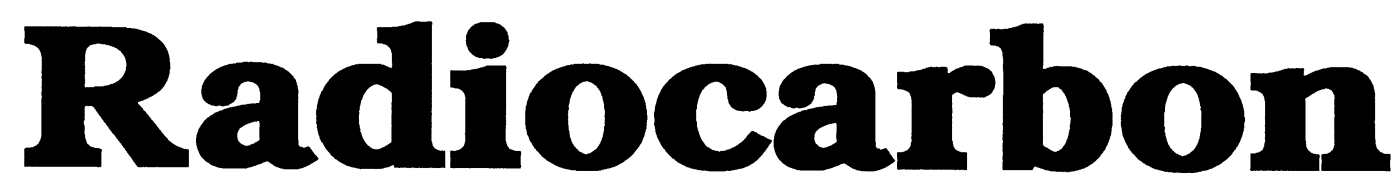

An International Journal of Cosmogenic Isotope Research

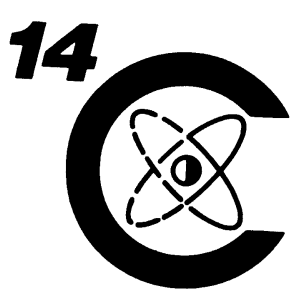

\section{Editor}

AUSTIN LONG

\section{Managing Editor}

RENEE S. KRA

\section{Assistant Editor}

FRANCES D. MOSKOVITZ

\section{Guest Editor}

PAUL E. DAMON

Paleoastrophysics, Paleogeophysics

Proceedings of the Workshop, Paleoastrophysics and Natural Variations of Cosmogenic Isotopes

Department of Geosciences

The University of Arizona 4717 East Ft. Lowell Road Tucson, Arizona 85712 USA 


\section{ASSOCIATE EDITORS}

For Accelerator Physics

DAVID ELMORE

ROBERT E. M. HEDGES

D. ERLE NELSON

For Archaeology

ANDREW M. T. MOORE

MICHAEL B. SCHIFFER

For Atmospheric Sciences

GEORGE A. DAWSON
KUNIHIKO KIGOSHI
DAVID C. LOWE

For Geochemistry

PAVEL POVINEC

MINZE STUIVER

For Geophysics
G. E. KOCHAROV
WILLEM G. MOOK

For Hydrology

JEAN-CHARLES FONTES

For Ice Studies

HAROLD W. BORNS, JR. ULRICH SIEGENTHALER

For Oceanography

EDOUARD BARD

ELLEN R. M. DRUFFEL

For Paleobotany

CALVIN J. HEUSSER
West Lafayette, Indiana, USA

Oxford, England

Burnaby, British Columbia, Canada

New Haven, Connecticut, USA

Tucson, Arizona, USA

Bratislava, Czecho-Slovakia

Seattle, Washington, USA

St. Petersburg, Russia

Groningen, The Netherlands

Orsay, France

Orono, Maine, USA

Berne, Switzerland

Gif-sur-Yvette, France

Palisades, New York, USA

Marseille, France

Woods Hole, Massachusetts, USA

Tuxedo, New York, USA 


\section{CONTENTS}

ACKNOWLEDGMENTS

\section{ARTICLES}

Implications of Dipole Moment Secular Variation from 50,000-10,000 Years for the Radiocarbon Record

$$
\text { R. S. Sternberg and P. E. Damon }
$$

The Sun as a Low-Frequency Harmonic Oscillator

P. E. Damon and J. L. Jirikowic

Reflection of Solar Activity Dynamics in Radionuclide Data

A. V. Blinov and M. N. Kremliovskij

Variation of Radiocarbon Content in Tree Rings During the Maunder Minimum of Solar Activity

G. E. Kocharov, A. N. Peristykh, P. G. Kereselidze, Z. N. Lomtatidze

R. Ya. Metskhvarishvili, Z. A. Tagauri, S. L. Tsereteli and I. V. Zhorzholiani

Subtle ${ }^{14} \mathrm{C}$ Signals: The Influence of Atmospheric Mixing, Growing Season

and In-Situ Production

Pieter M. Grootes

Cosmogenic Nuclides in Ice Sheets

Devendra Lal and A. J. T. Jull

Anomalous 11-Year $\Delta^{14} \mathrm{C}$ Cycle at High Latitudes?

P. E. Damon, George Burr, W. J. Cain and D. J. Donahue

A Supernova Shock Ensemble Model Using Vostok ${ }^{10} \mathrm{Be}$ Radioactivity

C. P. Sonett

Theoretical and Experimental Aspects of Solar Flares Manifestation in Radiocarbon

Abundance in Tree Rings

A. N. Kostantinov, V. A. Levchenko, G. E. Kocharov, I. B. Mikheeva

Stefano Cecchini, Menotti Galli, Teresa Nanni, Pavel Povinec

Livio Ruggiero and Agostino Salomoni

Recent and Historical Solar Proton Events

M. A. Shea and D. F. Smart

On a Plausible Physical Mechanism Linking the Maunder Minimum to the Little Ice Age

Elizabeth Nesme-Ribes and André Mangeney

A Tandem Mass-Spectrometric Method of Cosmogenic Isotope Analysis

A. K. Pavlov, V. T. Kogan and G. Y. Gladkov 